\title{
The Use and Analysis of Anti-Plagiarism Software: Turnitin Tool for Formative Assessment and Feedback $^{1}$
}

\author{
Malka N. Halgamuge \\ The University of Melbourne \\ Civil \& Environmental Engineering \\ School of Engineering \\ Grattan Street Melbourne Victoria \\ Australia 3010 \\ E-mail:malka.nisha@unimelb.edu.au
}

\footnotetext{
${ }^{1}$ This is the author manuscript accepted for publication and has undergone full peer review but has not been through the copyediting, typesetting, pagination and proofreading process, which may lead to differences between this version and the Version of Record. Please cite this article as doi:10.1002/cae.21842
}

This article is protected by copyright. All rights reserved. 
This analysis investigates the efficiency of the Turnitin software as a formative writing tool. The inquiry is especially looking into undergraduate and postgraduate students' experiences while using Turnitin. The perceptions and experiences of students will be prioritized in the study with the purpose of determining ways to improve Turnitin from students' point of view. Turnitin obtains text matches or similarity index values of 3173 assignments submitted on subjects uploaded between 2012-2014 by university students. We statistically analyzed the similarity index values or levels of plagiarism percentage between the first and the last assignments, using the two-sample Kolmogorov-Smirnov test, and we found that there was a significant improvement $(p=0.002)$. Hence, our results demonstrated that using Turnitin as a formative writing tool, allows students to prepare an assignment in an academically acceptable way, during the second half of the semester, with less plagiarism. The results found in this study suggests an insignificant difference between the draft version and final version of the same assignment $(p=0.192)$. Similarity index values are also different for different courses, such as writing based project subject and mathematics based engineering subject have different values $(p<0.0001)$. We also observed that students seem to be able to fool Turnitin tool by uploading images of the assignments instead of the text. Nevertheless, the nature of the subject, individual talent, learning approach, time contribution, and the exclusion of consecutive word count may affect the plagiarism percentage. Our results also indicate that there is a substantial benefit in using Turnitin as an educational writing tool rather than a punitive tool, as the use of Turnitin, promotes student learning outcomes with significantly improved academic skills. Thus, this paper provides an insight into avoiding high levels of plagiarism by using Turnitin as a preemptive tool.

\section{Index Terms}

Formative Assessment, Turnitin, assessment, plagiarism, formative writing tool

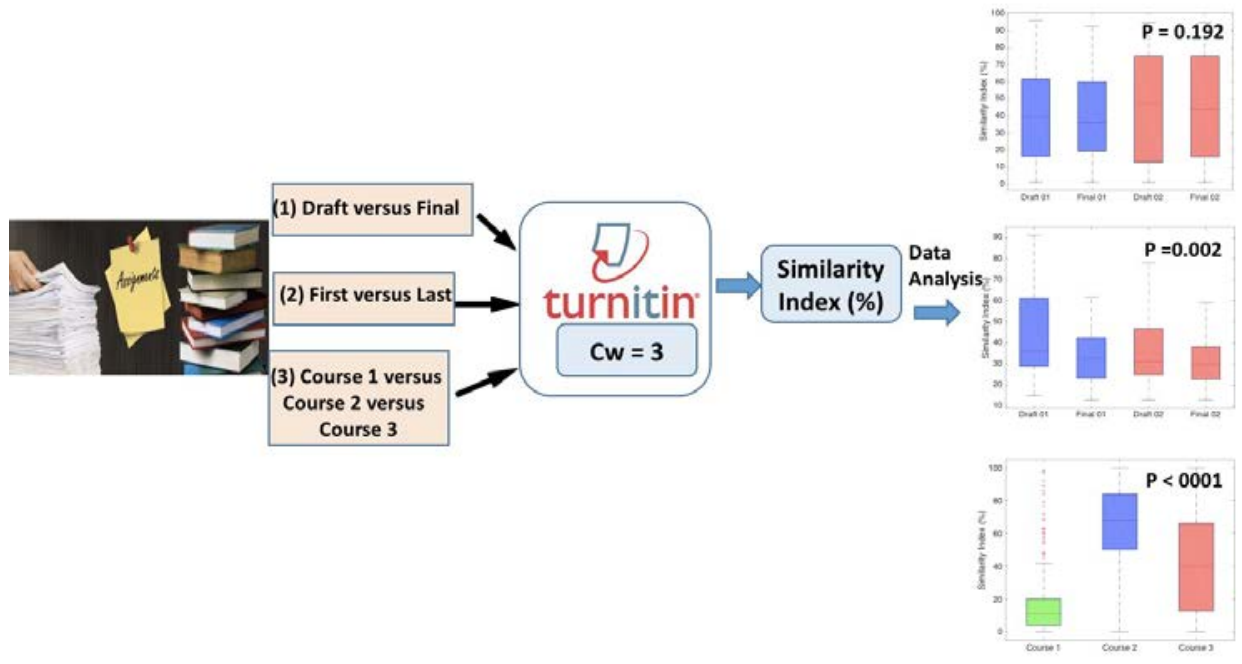

Fig. 1. Graphical summary: Analysis the use of anti-plagiarism software: Turnitin tool for formative assessment and feedback

\section{INTRODUCTION}

The growth rate of the Internet technology exceeds the progress rate of any other technology. This advancement is foreseeable due to the conveniences of the digital age. Technology also helps people to access the World Wide Web to navigating in exchange of valuable information. Technology has many advances for university students notwithstanding the opportunity to access materials related to their work through university libraries from anywhere in the world. The web is one of the most widespread services on the Internet that includes billions of documents called Web page (ITC, 2014). This promotes the freedom of exploiting or misrepresenting the online documents directly. Utilizing someone’s opinions or work without acknowledgments

is plagiarism. Turnitin is a valuable software (Turnitin.com) to support and to discover the plagiarism rate or ownership of the work to make sure of its academic truthfulness. Turnitin software detects plagiarism by identifying and comparing matching text among all the documents that have ever been published on the World Wide Web. Dr. John Barrie of the University of Berkeley, California developed the Turnitin plagiarism detection software and it has been used by numerous universities around the world, including Australia (iParadigms, 2004). The problem of plagiarism is reduced by introducing plagiarism detection software. The most known plagiarism detection tools are Turnitin, CopyCatchGold, Eve2, WordCheck, Glatt, Moss, JPlag, EduTie, PlagiServe, Google (Walker, 2010; James, 2002). However, Turnitin.com is the most popular software among all the present plagiarism software used in academia.

Plagiarism is an increasing problem amongst undergraduate and postgraduate students (Whittle, 2008). Hence, students should obtain an extensive training in academic writing in the first year of their course to understand and avoid plagiarism. Originality reports are generated from students' submitted assignments. Each report that is submitted to Turnitin is allocated an originality score; hence, a high score shows considerable matching text (similarity index values or levels of plagiarism percentage) (Cox, 2008). However, this has been a cause of criticism, as Turnitin has proven to be useful, particularly in-class 
to discourage plagiarism (Cohen, 2010; Rolfe, 2011). The opponent lecturers believe that plagiarism detection software increases their workload rather than benefiting individual students learning, as it is not a solution for the plagiarism (Smith, 2005). A previous study (Whittle, 2008) reported that $98 \%$ of students found that the Turnitin report was useful when they responded to a questionnaire. Some lecturers do not like to provide students' access to Turnitin reports, as it would allow students to discover other strategies to avoid detecting plagiarism (Goddard, 2005). Assessment tasks must be designed to measure the quality of the understanding of a subject, rather presenting repeated questions from previous years; hence, students are encouraged to recycle content from previous submissions (Cox, 2008). The primary aim of this work is to investigate the benefit and reliability of Turnitin to protect students' individual identity of their own work. A secondary aim is to determine other inputs to improve Turnitin program from the students point of view.

\section{A. University Policies of Turnitin Software}

Universities can adopt plagiarism policies to increase or decrease its impact. Nonetheless, it is critically important to ensure university standards about using Turnitin. Plagiarism should be undertaken principally; (i) integrating institutional policy (ii) practice and traditions of assessment design (iii) instruction of information for students; (iv) revealing; and finally, (v) with suitable ways of penalties (Carroll, 2002). The University of Melbourne has used Turnitin since July 2004 to support the University policies regarding the academic truthfulness of students work. The Turnitin software itself cannot make an opinion whether plagiarism has taken place. Determining the quality of the originality report and to review whether and how to identify parts by Turnitin are non-original or is not the responsibility of the lecturer (McPhee, 2007).

\section{B. Features of Turnitin Software and Its Impact on Student Learning}

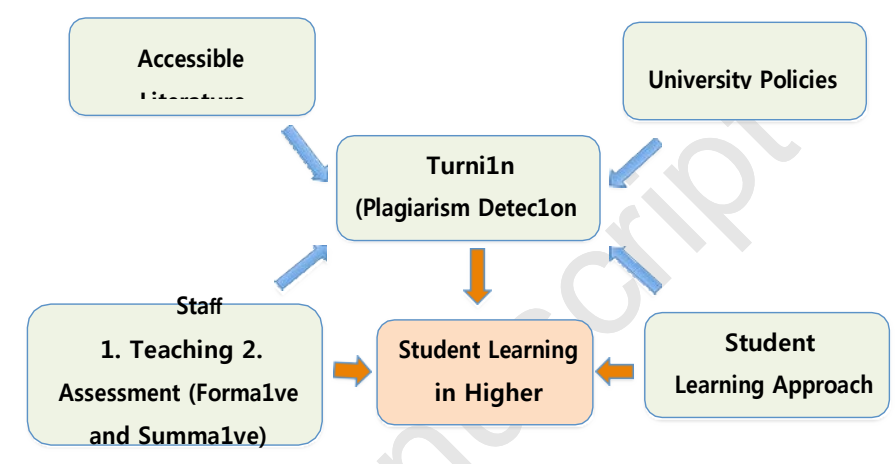

Fig. 2. Potential plagiarized sources (staff, student, university policies, accessible literature) on student work evaluation using Turnitin (plagiarism detection software). Please note that, formative and summative assessment methods, as well as deep and surface learning approaches, will be discussed in Section II.

The potential plagiarized parts in student assignments work are evaluated by using Turnitin, however, most commonly plagiarized sources are from: student, staff, accessible literature and university policies, as seen in Fig. 2 that Turnitin helps to identify the percentage of matching text in furtherance of identifying it by color and highlighted in-text. Additionally, it provides the URLs of the online documents. Hence, this helps students to be more methodical and vigilant in documenting sources and obtain maximum benefit from Turnitin as an academic writing tool. The Turnitin software only recognizes identical collections of text. It does not discern between texts that are referenced and texts that are not, hence, some of the text that has been referenced appropriately are considered as a plagiarized text (Smith, 2005). Possible advantages and disadvantages of the Turnitin software tool are described in Table I.

In the first part of this section, we explain how students' learning approaches should be improved to gain a better understanding of the subject content. In the second part of this section, we also show how principles of assessment criteria could be improved in furtherance of student learning. These are both critically and pedagogically important for improving student awareness.

\section{A. Deep and Surface Approach}

A "Deep" and "Surface" approaches are one of the two major learning approaches used in modern day academia (Ramsden, 2003; Biggs and Tang 2007). Learning quantity of the work with quality (deep approach) is better than learning quantity (surface approach) (Ramsden, 2003). The deep approach is extremely appropriate in some disciplines including engineering. Contrarily the surface learning approach is purely based on memorization of the inaccessible and unconnected items of the subject.

The fundamental role of a students' academic goals in self-motivated academic achievement was studied (Zimmerman, 1992; 1994) by using several path analysis procedures. A deep learning approach on students learning is undoubtedly one of the 
most practical strategies used in educational research, especially in the higher education. The learning processes without a deep approach in a study lead into erroneous outcomes. In principle, the deep approach of learning is better than the surface approach of learning and as lecturers' responsibility is to convey this message in a way that it inspires students to agree on a deep approach to learning.

1)

2) Deep Approach: The deep approach is associated with an objective to understand the content of the subject critically and try to make various links between concepts. Principally, there should be a motivation for what it is meant for students and scaffold knowledge from previous content. During this process, student builds their own opinion of the reality (Ramsden, 1988). The deep learning approach helps students to understand the content deeply, and connect it with previous knowledge, and it is a skill that is applied to life. On top of that deep approach uses student's active learning, not the passive learning, as this improves them academically by enhancing the student engagement with collaborative activities.

3) Surface Approach: The surface approach associated with an objective to complete the task. It does this by the requirements of memorizing facts without making various links between concepts. Instead of differentiating principles from evidence, students who are exposed to a surface learning approach try to memorize the content and procedures for their assessments (Ramsden, 1988). The surface learning approach makes students artificially remember subject material for the sole purpose of the examinations. However, this does not support long-term understanding of information.

The effects of deep and surface learning approaches of Turnitin are summarized in Table II. The main reason for a high Turnitin percentage is the surface learning approach. The Australian National University found extremely high rates of plagiarism that occurred for students with low levels of academic confidence (Marsden, 2001; 2005). This clearly shows the surface learning approach lead to high rates of plagiarism as a consequence of a wrong pedagogical approach. Another major reason for a high rate of plagiarism is that students do not have constructive learning strategies that allow students to build their own understanding from what they already know. On top of that, student retention is one of the main disputes facing Australian universities (Australian Education Council 1991:16).

These different approaches are not to change the students' behavior, instead, it changes their understanding and insight of the issue. This can be clearly seen from the Turnitin results. The surface approaches of learning are about accumulating detailed knowledge to satisfy a lecturer or to pass an examination. Opposite to this, the deep approach is about the rate of student engagement with the subject, as in applying theories in a contextual way (Biggs and Tang 2007). The vital change occurs by using the deep pedagogical approach, however, the consequences are quite adverse with the surface approach.

\section{B. Formative and Summative Assessment}

The purpose of the assessment should be to enhance the student learning outcomes although it is measured by students' knowledge and performance. The ranking and quality of the student's work are measured by the grade given for the assessment. Besides, this helps to show the student-learning patterns within the course throughout different disciplines, which could improve educational performances and teaching styles. Opposite to this, Barry (Barry, interview, 2004) identifies that the Turnitin software

TABLE III

EFFECT OF FORMATIVE \& SUMMATIVE ASSESSMENT OF TURNITIN

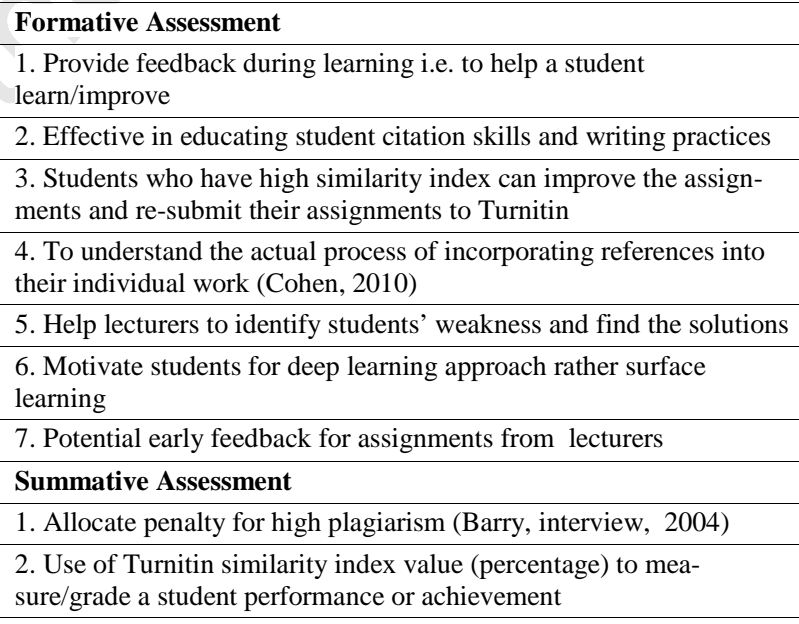

penalizes students rather than help them overcome problems with plagiarism. Table III describes the effect of formative and summative approach to the Turnitin assessment.

1) Formative Assessment: Observing student learning and providing continuing productive and comprehensible feedback on 
how to improve the learning of students is the purpose of formative assessments. This can be used for lecturers to improve their teaching in contemplation to improve their learning. The case study by Cohen (Cohen, 2010) analyzed how Turnitin software influences students' academic writing. Students who supported the use of Turnitin experienced that it helped them to understand the real processes of incorporating references into their individual work. Research shows that lecturers though that Turnitin is useful in class to discourage plagiarism (Cohen, 2010) and to make it easier to identify plagiarized material. The recent case study (Sivasubramaniam, 2006) shows that plagiarism is the results in the lack of academic writing needs and the lack of a deep learning approach. It is important to encourage lecturers and students to use Turnitin as a formative tool to help academic writing (Bostock, 2014). Hence, comprehensive formative workshops on developing of these academic writing skills are significantly important.

2) Summative Assessment: Summative assessment is the comparison of a model answer to an assignment or unit to create a grade. This is for creating an accurate and precise grade for a student development and understanding for a particular point of time. This means the mark given by summative assessments is much more significant and creates a highly competitive atmosphere.

\section{MATERIALS AND METHODS}

For this preliminary study, we collected 3173 datasets using 14 subjects from university students. In this section, we observe the principles discussed in the previous sections about how to use Turnitin (plagiarism detection software) to obtain similarity index values or text matching from 3173 assignments from university undergraduate and postgraduate students. Then we use a few statistical analysis methods to explore the collected data and to observe the trend of plagiarism. Then we obtain theoretical analysis to show how plagiarism detection software could be beneficial to students learning.

\section{A. Experiment Set Up}

We collected data and analyzed the significance of the Turnitin software tool to improve academic writing in higher education. For our analysis, we used the Turnitin software tool to obtain the similarity index values or text matching from 3173 assignments submitted using 14 subjects uploaded between 2012-2014 from university undergraduate and postgraduate students. Please note that, students' draft assignments, as well as final assignments, are placed into the Turnitin.com database, however, in two different folders. The draft assignments were not saved in the "standard paper repository", so these disclose when counting plagiarism content in students' final assignments. Otherwise, draft assignments could impact the recognition of plagiarized material in subsequent submissions of final assignments.

Citation, referencing guidance, and text colored rubrics were given when discussing the assignment questions. The draft assignment folder option was created to their plagiarism percentages so students can fix it and then submit to the final assignment folder. This allows students to submit multiple times until they are satisfied with their plagiarism percentage before the due date of their assignment. In our analysis, we fixed the consecutive word count to be excluded in the matching text as $C_{w}=$ 3 (as proposed in (Lyon, 2006)). On top of this, the option of viewing originality report was allowed for each student to amend their drafts. Using this feature, students can revise their plagiarized text and lower the similarity index value in the final

submission of the same assignment, and this process becomes a learning curve to obtain academic writing skills. There are a few limitations of this study. For this analysis, we assume: (i) Students improvement in academic writing was not due to the coursework and/or writing workshops that was a part of the course (ii) Students were unable to receive feedback from course instructors or university writing centers for their assignments.

In our analysis, the scheme for different similarity index $\left(S_{i}\right)$ is categorized, as in Table IV. We used no penalty for the students who receive similarity index between $0-24 \%$ while the highest penalty is given for similarity index between $75-100 \%$. As proposed in (Lyon, 2006), we used the consecutive words, $C_{w}=3$ for this study.

The probability distribution of the similarity index or plagiarism content is observed to test the normality of the distribution. The data was not normally distributed, therefore, the geometric mean (GM) and geometric standard deviation (GSD) are more applicable than the arithmetic mean (AM) and standard deviation (SD) for explaining the relative distribution of the magnetic fields. Hence, for the comparison, we used the GM and GSD values.

The interquartile range (IQR) is a vigorous estimate of the spread of the data, as changes in the upper and lower $25 \%$ of the data do not affect it. As an estimate, the IQR is more representative than the standard deviation of the spread of the data, if there are outliers in the data. When the data is from the normal distribution, the IQR is less efficient than the standard deviation as an estimate of the spread. However, we found our data is not normally distributed. Therefore, we analyzed the interquartile range of the datasets (similarity index values) to observe how data spreads over the 25th (first quartile, Q1) and 75th (third quartile, Q3) percentiles. In pursuance to estimate outliers, Q1 and Q3 will be used. Hence, any value outside this range is defined as the outlier (below Q1 1.5 IQR or above Q3 + 1.5 IQR).

All analysis was carried out using MATLAB R2015b on an Intel Core i7 CPU. The IQR estimate is calculated by $\Theta_{I Q R}=$ ก 75 IQR of the given dataset. Then, as in (Halgamuge, 2014), the efficiency $(\eta)$ of using Monte Carlo simulation is computed by 
$\eta=\left(\frac{\|\sigma-1\|}{\left\|\Theta_{I Q R}-1\right\|}\right)^{2}$,

where the standard deviation of the data is $\sigma$.

This article is protected by copyright. All rights reserved. 
We then compared the similarity index values $\left(S_{i}\right)$ of assignments when similarity index is $0-24 \%$ no penalty is allocated $(N P)$ while penalties are given for all other similarity index percentages $\left(P_{\max }, P_{a v g}, P_{\min }\right)$. The probability values $(p$-values) for each comparison is determined by using the two-sample Kolmogorov-Smirnov test. Results a statistically show a significant different at $p<0.05$ and statistically highly significant differences at $p<0.0001$. The null hypotheses that the similarity index values of the two samples are from the same continuous distribution, using the two-sample Kolmogorov-Smirnov test. The alternative hypothesis is that the similarity index values of the two samples are from different continuous distributions. The result $H=1$ if the test rejects the null hypothesis at the $5 \%$ significance level, and $H=0$ otherwise.

\section{B. Theoretical Analysis}

Lecturers have the preference (i) to allow students to see their originality report or not, after submitting work to Turnitin, (ii) to allow single or multiple submissions (students can revise their work and resubmit to Turnitin) (iii) exclusion of consecutive word count (based on the subject exclusion of consecutive word count could be two or three) and (iv) to create different folders for the draft and the final copy. Color coded versions of the submission highlight the text which matches other sources with the relevant percentage in the originality report and whether adequately referenced or not it still in color codes. Nonetheless, students, as well as lecturers, are responsible for students' high plagiarism percentage as shown in Table Table VI. In consideration of these facts (as seen in Table VI), we can show the similarity index as a function of below parameters and define it with Similarity Index, $S_{i}=f$ (nature of the subject, individual talent, learning approach, time contribution, exclusion of consecutive word count), where $n$ is the nature of the subject, $T$ is the individual talent, $l$ is the learning approach, $t$ is the time contribution for the subject and the exclusion of consecutive word count, $C_{w}$.

The approach can be given by

$$
S_{i}=f(n, T, l, t, C w) .
$$

Turnitin software matches texts by color highlighted in the text and this is exceptionally useful. Therefore, students can straightforwardly re-write the plagiarized text and re-submit the assignment that would obviously lead low similarity index. In addition, lecturers can clearly identify similarity of match by checking the color code without opening the document as green indicates insignificant and red is significant. Using this feature on the Turnitin software could reasonably improve students' second and thirds assignments, towards the end of the semester. The step-by-step method of data analysis is shown in Algorithm 1.

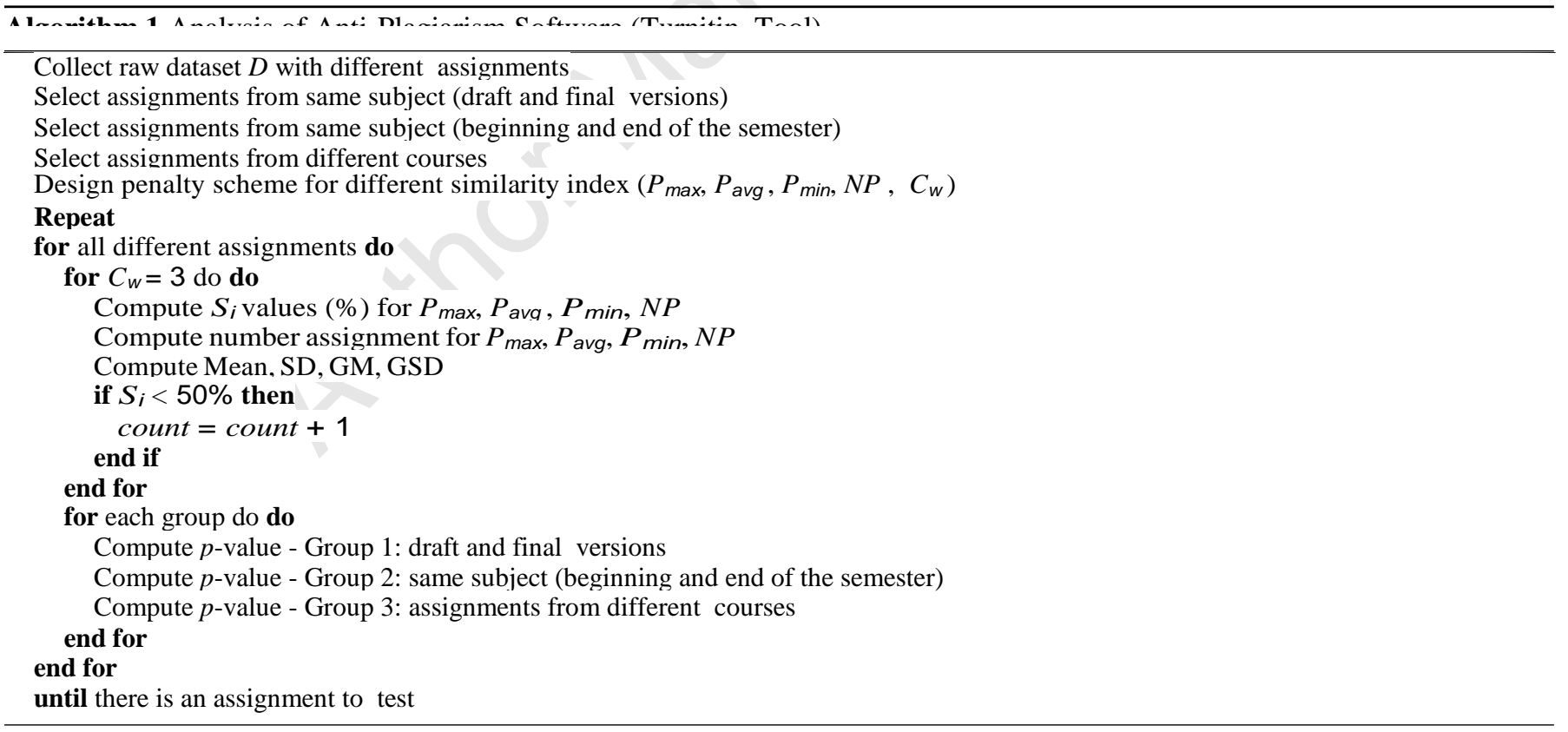

\section{RESUltS AND Discussion}

Our experimental data analysis agrees with the above theoretical analysis and will be discussed in details this section. The sample size (3173 assignments submitted are used in this study. Table V shows the comparisons between different submissions (draft and final) of the similarity index values. The descriptive statistics and the similarity index is less than $50 \%$ of draft and final submissions of the assignments are calculated in Table VII.

We plotted the similarity index values by 11 subjects in order to observe the distribution pattern. Figure 3 shows box plots This article is protected by copyright. All rights reserved. 
with median and interquartile range for 48 different assignments of 11 subjects. The T-bars (whiskers) were extended to 1.5times the height of the box (IQR). A + symbol depicts values are more than three IQRs from the end of the box (the extreme outlier). The normal probability values are computed from the formula explained in the Appendix. Overall, the average similarity index values that obtained by students were in the range of $8.28-72.41 \%$ (AM) and $5.92-70.40 \%$ (GM) for the draft assignment while 16.10 - 73.17\% (AM) and 11.68 - 69.17\% (GM) for the draft assignment.

Results indicate that students have learned how to write academically from the first assignment. This gave them the chance to improve themselves further with the second assignment, especially later in the semester. However, our results also show that some students try to avoid submitting the assignments to the given plagiarism detection software. Additionally, confirmed that larger number of international students received high plagiarism index. One of the potential reasons for this could be the language difficulty for international students, as they are using English as a second language. Besides, students indicated the usefulness of seeing their originality reports that show how much of their work is matched up with others texts from the internet. The correct learning approach, such as the deep learning approach, changes the attitudes of students towards the learning and understanding of a subject content.

Interestingly, results indicated that students have learned how to write academically, rather than depending on poor paraphrasing or using direct quotations, from the first assignment, and showed improvements in the second assignment towards the end of the semester. Nonetheless, results show a higher number of international students were affected by high plagiarism index. During the discussion with students, at the end of the semester, it was revealed that students had access to their originality report which was significantly beneficial. Additionally, from our analysis, we observed the reason for high rates of plagiarism were not only because it depended on students laziness of learning, but it was also due to the nature of the problems in assignments. For example, students required to answer short questions that would be learning to answer questions in the nature 
Draft 01 Final 01 Draft 02 Final 02

This article is protected by copyright. All rights reserved. 
Draft 01 Final 01 Draft 02 Final 02

(a) Subject A (\# Data = 179): Draft and final submission of Assignments 1 and 2

This article is protected by copyright. All rights reserved. 
(c) Subject C (\# Data = 308): Draft and final submission of Assignments 1 and 2

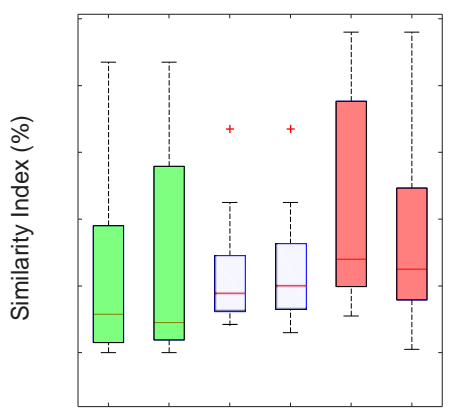

100

This article is protected by copyright. All rights reserved. 
Draft 01 Final 01 Draft 02 Final 02

This article is protected by copyright. All rights reserved. 
(f) Subject F (\# Data = 497): Draft and final submission of Assignments 1, 2 and 3

(g)

(h)

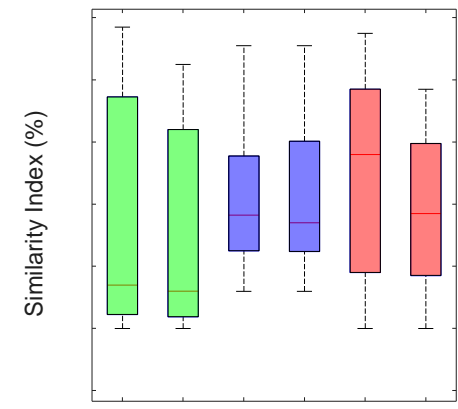

100

80

This article is protected by copyright. All rights reserved. 
Draft 1Final 1Draft 2Final 2Draft 3Final3

This article is protected by copyright. All rights reserved. 

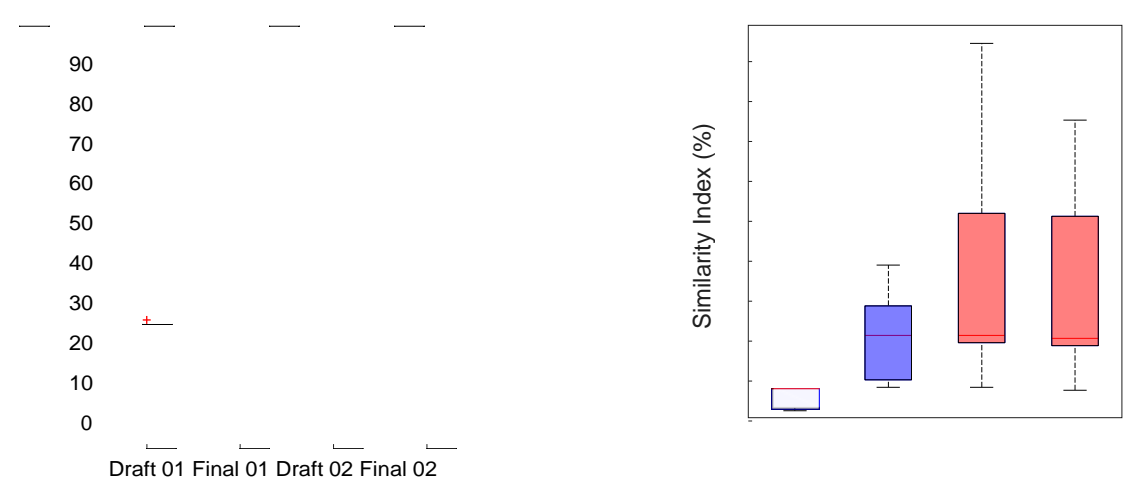

Draft 01 Final 01 Draft 02 Final 02

This article is protected by copyright. All rights reserved. 
Draft 01 Final 01 Draft 02 Final 02

(i) Subject G (\# Data = 66): Draft and final submission of Assignments 1, 2 and 3

This article is protected by copyright. All rights reserved. 

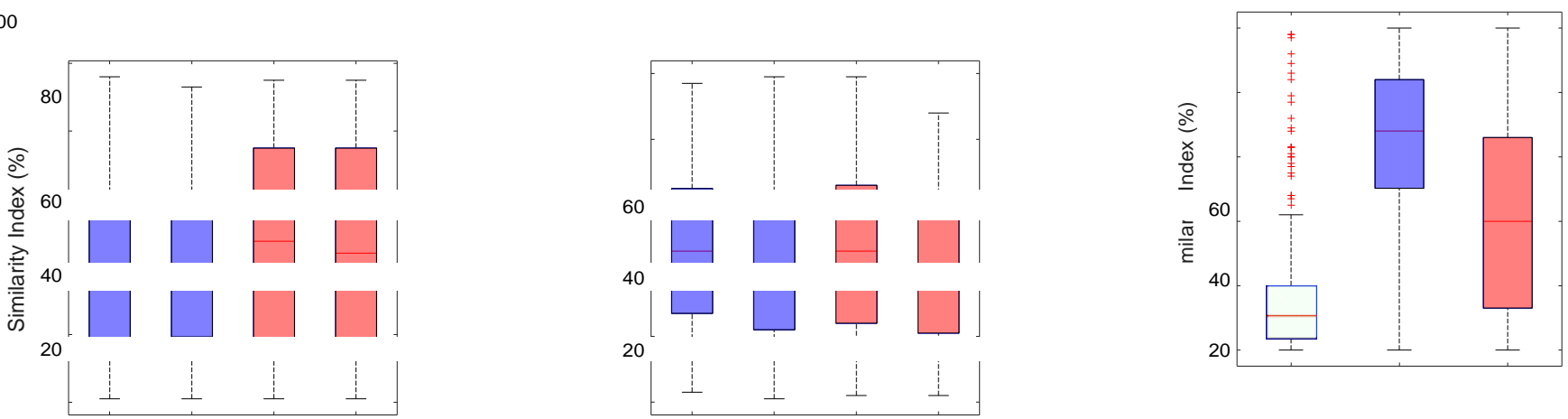

0

Draft 01 Final 01 Draft 02 Final 02

This article is protected by copyright. All rights reserved. 
(p) Subject L, M \& N (\# Data = 1111): Course 1 (more theory), Course 2 (more mathematics) and Course3(both theory and mathematics)

(q)

(r)

Fig. 3. Box plots with median and interquartile range for 51 different assignments of 14 subjects. The T-bars (whiskers) were extended to 1.5times the height of the box (IQR). A “+” symbol depicts a value more than three IQRs from the end of the box (the extreme outlier).

The calculated probability values ( $p$-values) are shown in Table VIII using the two-sample Kolmogorov-Smirnov test. The results demonstrate that there was no statistically significant difference $(p=0.192)$ between the draft and final submission of the same assignment. This clearly shows that the majority of students did not take much effort in getting a low similarity index to improve the assignment within a short period of time. Nonetheless, using this feature on the Turnitin software, improved students second assignments, reasonably. Moreover, the results show there is a statistically significant difference $(p=0.002)$ on similarity index between the first assignment (that has been submitted during the early semester) and the last assignment (that is submitted at the end of the semester). This clearly shows that after a few weeks of learning the subject, student gained knowledge on how to write academically without having plagiarism percentage.

It is well-known that depending on the subject, the reuse of the materials is expected to be higher (compilations about a topic) or lower (free topic like a press article, dissertation or a letter). Hence, it would be interesting to observe the behavior (similarity)

of the students in the same courses using Turnitin values and not using it. This could give us a more reliable comparison of reducing similarity (possible plagiarism), nonetheless, it does not mean their writing skills will improve. Moreover, a comparison of the marks of these two scenarios could be a fair comparison of the impact of Turnitin on better writing skills. It is expected an improvement of the skills during the course, the comparison can show non-significance differences between the main premise of the paper. Hence, we used the comparison of three subjects (project writing (small dissertation) and mathematical based engineering subject). Please see the Figure 2(i). The results show this comparison is highly statistical significance $(p<0.0001)$.

Therefore, the need for compulsory academic writing workshops before starting an undergraduate course should be a prerequisite. The postgraduate courses would also benefit from a prerequisite subject. Contrary to this, Turnitin software,

TABLE VII

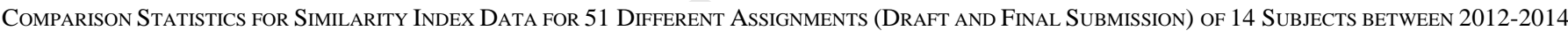
EVALUATION OF ASSIGNMENTS IN EACH SEMESTER

\begin{tabular}{|l|l|l|}
\hline Options & p-value & $\begin{array}{l}\text { Statistically Signifi- } \\
\text { cant or Not }\end{array}$ \\
\hline $\begin{array}{l}\text { Draft versus final submission } \\
\text { of each assessment }\end{array}$ & 0.192 & Not significant \\
\hline $\begin{array}{l}\text { First assignment by early } \\
\text { semester and last assignment } \\
\text { by the late semester }\end{array}$ & $\mathbf{0 . 0 0 2}$ & Significant \\
\hline Course 1 versus Course 2 & $<\mathbf{0 . 0 0 0 1}$ & Highly Significant \\
\hline Course 2 versus Course 3 & $<\mathbf{0 . 0 0 0 1}$ & Highly Significant \\
\hline Course 1 versus Course 3 & $<\mathbf{0 . 0 0 0 1}$ & Highly Significant \\
\hline
\end{tabular}

for example, is quite controversial, as it has been stealing from others intellectual property rights by automatically adding students' assignments to their database (Horovitz, 2008). Most universities face the challenges of encouraging honesty and respect for work of others and for safeguarding the integrity of the learning and grading procedures (Horovitz, 2008).

Moreover, we used the consecutive words, $C_{W}=3$ for this study, however, we observed that the impact of the $C_{W}$ for the similarity index. The optimal number of $C_{w}$ depends on the assignment questions. Hence, a lecture can use different $C_{w}$ values for a different subject, such as writing based project subject with low $C_{W}$ and mathematics based engineering subject with high $C_{W}$ to balance the similarity index percentage.

\section{A. Suggested Improvements for Turnitin Software}

1) Faster matching speed so that students can quickly check their plagiarism percentage of their assignment before submitting 
the final document.

2) The web design needs to be more attractive.

3) Submitting options needs to improve as students make mistake by submitting assignments to wrong subjects.

4) Content matching, especially for formula, needs to improve.

5) Improve the software to avoid direct quoted or paraphrased text as plagiarized work.

6) File submission options are needed to support more flexible submission options such as allowing students need to upload multiple files for an assignment and it needs to support more file types.

An amount of class time should be allocated for explaining the Turnitin originality reports comprehensively in a structured manner. Future research on how students can gradually receive a minimum plagiarism percentage indicated their increased referencing and writing abilities developed over time would be useful for students. Some students seem to accept the penalty for not submitting the assignment for plagiarism detection software, rather than getting the penalty for being plagiarized. Moreover, the consequences of the surface approach on the plagiarism index would also be of interest if further explored.

Hence, closer observation of University policies in using Turnitin, specifically the features dealing with formative experiences of the Turnitin software would be an advantage for students, as well as lecturers. Finally, lecturers should encourage students to use Turnitin as an educational writing tool rather than a punitive tool. Hence the student-learning outcome can improve, drastically when the aforementioned factors are considered. However, there are criticisms about plagiarism detection software programs currently being used students actually rot the system by applying a google translate to a piece of writing in their own language and translate it into English which Turnitin does not recognize (Mozgovoy, 2007).

\section{B. Comparison of Plagiarism Detection Tools}

Computer science is the fastest growing technology. The Internet usage continues to grow at a rapid rate worldwide. The World Wide Web is one of the most widespread services on the Internet that includes billions of web pages. Exploiting or misrepresenting the online documents without citations can lead to plagiarism. Turnitin is the most successful online software tool for identifying plagiarism by comparing matching text between different documents on the web. Hence, it is important to understand issues in using Turnitin as a tool to detect plagiarism. However, various tools are available for plagiarism detection in documents published in World Wide Web. The most known plagiarism detection tools are Turnitin, CopyCatchGold, Eve2, WordCheck, Glatt, Moss, JPlag, Google (James, 2002). Due to its good functionality, Turnitin is known as the most widespread detection tool among others (Lukashenko, 2007). A different set of features is used to determine which tool is the suitable for diverse applications. James et al (2002) have shown this extensively. The summary of this comparison is given by

1) Check with web: Turnitin, Eve2, Glatt, Jplag, Google

2) Check with own database: Turnitin, WordCheck, Moss, JPlag

3) Cross-checks with other students' work: Turnitin, CopyCatchGold, WordCheck, JPlag

4) Aimed for use by students: Turnitin, Google

5) Aimed for use by Lecturers: Turnitin, CopyCatchGold, Eve2, WordCheck, Glatt, Moss, JPlag, Google

6) Quick response about plagiarism: Eve2, WordCheck, Google

7) Free: Moss, JPlag, Google

\section{CONCLUSION}

Turnitin is a valuable software tool that helps to identify plagiarism or the ownership of written work. In this paper, we evaluated the impact of Turnitin on students writing perspective and we found that students learned how to prepare assignments in an academically acceptable way. The results indicated that, especially, during the second half of the semester, plagiarism rates were lesser, by using Turnitin as a formative writing tool $(p=0.002)$. Similarity index values or levels of plagiarism percentage might differ for different courses, such as writing based project subject and mathematics based engineering subject $(p<0.0001)$. Our results also indicated that high numbers of international students had difficulties with academic writing, as they are using English as a second language. Consequently, their work found to have a trend of higher levels of plagiarism percentage. Students indicated the usefulness of seeing their originality scored and understanding how their work compares

with other texts from the internet. While acknowledging this primary benefit, our article also suggests that the nature of the subject, the individual talent, learning approach and the time contribution can affect the individual plagiarism percentage. There is a substantial benefit in using Turnitin as an educational writing tool rather than a punitive tool, and student learning outcomes can be significantly improved, and this process becomes a learning curve to acquire academic writing skills. The compulsory academic writing workshops held at the start of the undergraduate and the postgraduate courses are expected to be beneficial as well. Though the assignment sample size, in this analysis, is small in the statistical significant sense, it provides useful insight. Based on these findings, the article suggests a need for further surveys to be conducted with larger sample sizes and independent surveys to verify our observations. 


\section{ACKNOWLEDGEMENT}

Graduate Certificate in University Teaching (GCUT) course, Centre of the Study of Higher Education (CSHE), Faculty of Education, The University of Melbourne, and School of Computing \& Mathematics, Charles Sturt University, Melbourne, Australia.

\section{DECLARATION OF INTEREST}

The authors report no conflicts of interest.

\section{APPENDIX}

The geometric mean (GM) is more relevant than the arithmetic mean for explaining the relative progress of the expected similarity index values. The GM of each dataset to estimate of the population can be computed using the below formula. The GM of the measured magnetic fields of a data set $x_{i}=x_{1}, x_{2}, \cdots, x_{n}, G M_{x}$ is given by

$G M_{x}=\left[\prod_{i=1}^{n} x_{i}\right]^{\frac{1}{n}}$.

Using (2) geometric standard deviation, $G S D_{x}$ is given by 
1. Simple: The software is easy to use and it does not take much time (just about 10 minutes) for students to learn how to use it to submit and re-submit the assignment, checking where was the similarity between their assignments and the one submitted in the past.

2. Fast: The results show the similarity percentage within 5-10 minutes, though it can go high up to days, depending on the condition of the system. This is generally reasonable enough and the upload speed which is also good.

3. Easy to access: Turnitin is a web-based application which generally can access from many types of browser such as Internet Explorer, Google Crome, Firefox and Safari from anywhere allows students to easily submit their assignments from home, workplace or at University.

4. Assignment marking and grading using rubrics: The digital mark-up tool is allowed to correct and grade assignments on-line in pdf or doc files. Therefore, no paper assignments are required to submit.

5. Excellent coverage of sources: Turnitin covers a vast range of Internet documents.

Disadvantages

1. “Unintelligent” content matching: Turnitin matches everything, including mathematical formula. This is unintelligent because many assignments are for the same assignment question, which contains a lot of mathematical formula. However, Turnitin is not intelligent enough to recognize that formula and they should not count for that formula for matching contents.

2. Including directly quoted text: Use directly quoted or paraphrased text as plagiarized work.

3. Limited size of uploaded files: File size restriction is $10 \mathrm{MB}$, as this is especially bad for assignments containing graphic elements cannot be uploaded.

4. Limited file submission options: Turnitin only accepts doc and PDF files. More file types should be supported so that students have the flexibility to upload their work. Moreover, students should be able to submit multiple files for their assignments in a single upload. This is considerably important, for an example, accounting students who want to submit their words + Excel + JPEG files in their assignment at the same time should be able to do so.

5. Boring appearance and user interface: Though it is only the portal for submitting an assignment, it should look more interesting. This can make students feel more interested in their work.

6. Fool the software system: According to our practice, students seem to be able to fool the software by uploading images of the work instead of text. Therefore, students can obtain the $0 \%$ similarity index.

\section{Theoretical Reasoning: Learning and Assessment}

TABLE IIDEEP AND SURFACE LEARNING APPROACH

\begin{tabular}{|l|}
\hline Deep Learning Approach \\
\hline $\begin{array}{l}\text { 1. Objective is to understand the content of the subject, enthusiasti- } \\
\text { cally }\end{array}$ \\
\hline 2. Interrelate dynamically with the content of the subject \\
\hline 3. Share new concepts to prior knowledge (Ramsden, 1988) \\
\hline $\begin{array}{l}\text { 4. Students are inspired by their own interest to the subject and } \\
\text { establish positive experience }\end{array}$ \\
\hline $\begin{array}{l}\text { 5. Deeper interaction with the subject lecturer and build-up student's } \\
\text { confidence }\end{array}$ \\
\hline 6. Manage to read beyond and study outside the course requirement \\
\hline Surface Learning Approach \\
\hline 1. Objective is to complete the task requirements \\
\hline 2. Less constructivism (Australian Education Council 1991:16) \\
\hline 3. Low levels of academic confidence (Marsden, 2001; 2005) \\
\hline $\begin{array}{l}\text { 4. Failure to differentiate principles from evidence (Ramsden, 1988) } \\
\text { and examples }\end{array}$ \\
\hline 5. Failure to explore boundaries of the given topic \\
\hline
\end{tabular}


TABLE IVPENALTY SCHEME FOR DIFFERENT SIMILARITY INDEX

\begin{tabular}{|l|l|l|}
\hline Parameter & Notation & Value \\
\hline Similarity Index $\left(S_{\boldsymbol{i}}\right)$ for maximum penalty & $\boldsymbol{P}_{\max }$ & $75-100 \%$ \\
\hline Similarity Index $\left(\boldsymbol{S}_{\boldsymbol{i}}\right)$ for average penalty & $\boldsymbol{P}_{\text {avg }}$ & $50-74 \%$ \\
\hline Similarity Index $\left(\boldsymbol{S}_{\boldsymbol{i}}\right)$ for minimum penalty & $\boldsymbol{P}_{\min }$ & $25-49 \%$ \\
\hline Similarity Index $\left(\boldsymbol{S}_{\boldsymbol{i}}\right)$ for no penalty & $N P$ & $0-24 \%$ \\
\hline $\begin{array}{l}\text { Exclusion of consecutive word count (con- } \\
\text { secutive words) }\end{array}$ & $C_{W}$ & 3 \\
\hline
\end{tabular}

\section{Statistical Analysis}

TABLE VSIMILARITY INDEX VALUES FROM 48 DIFFERENT ASSIGNMENTS (11 SUBJECTS) DURING 2012-2014

\begin{tabular}{|c|c|c|c|c|c|c|c|c|c|c|}
\hline \multirow{2}{*}{$\begin{array}{l}\text { Assignment } \\
\text { No }\end{array}$} & \multicolumn{5}{|c|}{ Number of Draft Submissions } & \multicolumn{5}{|c|}{ Number of Final Submissions } \\
\hline & $\begin{array}{l}\text { Sample } \\
\text { Size }\end{array}$ & $\begin{array}{l}\text { 75-100 \% } \\
\left(P_{\max }\right)\end{array}$ & $\begin{array}{l}\mathbf{5 0 - 7 4} \% \\
\left(P_{\text {avg }}\right)\end{array}$ & $\begin{array}{l}25-49 \% \\
\left(P_{\min }\right)\end{array}$ & $\begin{array}{l}\text { 0-24 \% } \\
(N P)\end{array}$ & $\begin{array}{l}\text { Sample } \\
\text { Size }\end{array}$ & $\begin{array}{l}75-100 \% \\
\left(P_{\max }\right)\end{array}$ & $\begin{array}{l}\mathbf{5 0 - 7 4} \% \\
\left(P_{\text {avg }}\right)\end{array}$ & $\begin{array}{l}25-49 \% \\
\left(P_{\min }\right)\end{array}$ & $\begin{array}{l}\mathbf{0 - 2 4} \% \\
(N P)\end{array}$ \\
\hline \multicolumn{11}{|c|}{ Subject $\mathrm{A}$} \\
\hline Assignment 01 & 44 & 17 & 17 & 10 & 0 & 50 & 16 & 22 & 11 & 1 \\
\hline Assignment 02 & 37 & 12 & 15 & 7 & 3 & 48 & 19 & 17 & 9 & 3 \\
\hline Sub-total & 81 & 29 & 32 & 17 & 3 & 98 & 35 & 39 & 20 & 4 \\
\hline \multicolumn{11}{|c|}{ Subject B } \\
\hline Assignment 01 & 17 & 9 & 7 & 1 & 0 & 18 & 9 & 7 & 1 & 1 \\
\hline Assignment 02 & 10 & 3 & 6 & 1 & 0 & 15 & 8 & 7 & 1 & 1 \\
\hline Sub-total & 27 & 12 & 13 & 2 & $\mathbf{0}$ & 35 & 17 & 14 & 2 & 2 \\
\hline \multicolumn{11}{|c|}{ Subject C } \\
\hline Assignment 01 & 85 & 28 & 20 & 19 & 18 & 79 & 19 & 15 & 25 & 19 \\
\hline Assignment 02 & 74 & 23 & 19 & 18 & 14 & 71 & 18 & 17 & 20 & 16 \\
\hline Sub-total & 159 & 51 & 39 & 37 & 32 & 149 & 37 & 32 & 45 & 35 \\
\hline \multicolumn{11}{|c|}{ Subject D } \\
\hline Assignment 01 & 14 & 1 & 2 & 1 & 10 & 17 & 2 & 3 & 2 & 10 \\
\hline Assignment 02 & 18 & 0 & 1 & 5 & 12 & 21 & 0 & 1 & 8 & 12 \\
\hline Assignment 03 & 15 & 4 & 0 & 5 & 6 & 17 & 3 & 1 & 5 & 8 \\
\hline Sub-total & 47 & 5 & 3 & 11 & 28 & 55 & 5 & 5 & 15 & 30 \\
\hline \multicolumn{11}{|c|}{ Subject E } \\
\hline Assignment 01 & 11 & 2 & 2 & 5 & 2 & 11 & 0 & 1 & 7 & 3 \\
\hline Assignment 02 & 11 & 1 & 1 & 7 & 2 & 11 & 0 & 1 & 7 & 3 \\
\hline Sub-total & 22 & 3 & 3 & 12 & 4 & 22 & $\mathbf{0}$ & 2 & 14 & 6 \\
\hline \multicolumn{11}{|c|}{ Subject $\mathbf{F}$} \\
\hline Assignment 01 & 141 & 39 & 63 & 28 & 11 & 141 & 33 & 64 & 32 & 12 \\
\hline Assignment 02 & 95 & 45 & 33 & 14 & 3 & 120 & 72 & 31 & 13 & 4 \\
\hline Sub-total & 236 & 84 & 96 & 42 & 14 & 261 & 105 & 95 & 45 & 16 \\
\hline \multicolumn{11}{|c|}{ Subject G } \\
\hline Assignment 01 & 12 & 3 & 1 & 1 & 7 & 11 & 3 & 0 & 1 & 7 \\
\hline Assignment 02 & 12 & 2 & 1 & 6 & 3 & 13 & 2 & 2 & 6 & 3 \\
\hline Assignment 03 & 10 & 3 & 3 & 1 & 3 & 8 & 1 & 1 & 3 & 3 \\
\hline Sub-total & 34 & 8 & 5 & 8 & 13 & 32 & 6 & 3 & 10 & 13 \\
\hline \multicolumn{11}{|c|}{ Subject $\mathbf{H}$} \\
\hline Assignment 01 & 7 & 0 & 0 & 1 & 6 & 10 & 0 & 0 & 2 & 8 \\
\hline Assignment 02 & 10 & 1 & 1 & 2 & 6 & 10 & 1 & 1 & 1 & 7 \\
\hline Sub-total & 17 & 1 & 1 & 3 & 12 & 20 & 1 & 1 & 3 & 15 \\
\hline \multicolumn{11}{|c|}{ Subject I } \\
\hline Assignment 01 & 50 & 8 & 5 & 10 & 27 & 50 & 7 & 2 & 10 & 31 \\
\hline
\end{tabular}

This article is protected by copyright. All rights reserved. 


\begin{tabular}{|c|c|c|c|c|c|c|c|c|c|c|}
\hline Assignment 02 & 48 & 6 & 5 & 10 & 27 & 48 & 5 & 2 & 10 & 31 \\
\hline Sub-total & 98 & 14 & 10 & 20 & 54 & 98 & 12 & 4 & 20 & 62 \\
\hline \multicolumn{11}{|c|}{ Subject J } \\
\hline Assignment 01 & 32 & 5 & 6 & 11 & 10 & 31 & 3 & 7 & 11 & 10 \\
\hline Assignment 02 & 24 & 7 & 5 & 4 & 8 & 27 & 8 & 5 & 6 & 8 \\
\hline Sub-total & 56 & 12 & 11 & 15 & 18 & 58 & 11 & 12 & 17 & 18 \\
\hline \multicolumn{11}{|c|}{ Subject K } \\
\hline Assignment 01 & 124 & 19 & 34 & 43 & 28 & 122 & 8 & 33 & 46 & 35 \\
\hline Assignment 02 & 109 & 19 & 30 & 32 & 28 & 103 & 10 & 26 & 32 & 35 \\
\hline Sub-total & 233 & 38 & 64 & 75 & 56 & 225 & 18 & 59 & 78 & 70 \\
\hline Total & 1010 & 257 & 277 & 242 & 234 & 1052 & 247 & 266 & 269 & 271 \\
\hline
\end{tabular}

TABLE ViPossible Reasons for High Plagiarism Percentage

\begin{tabular}{|l|l|l|}
\hline $\begin{array}{l}\text { Possible Reasons for High Plagiarism } \\
\text { Percentage }\end{array}$ & $\begin{array}{l}\text { Student } \\
\text { Responsi- } \\
\text { ble }\end{array}$ & $\begin{array}{l}\text { Lecturer } \\
\text { Responsi- } \\
\text { ble }\end{array}$ \\
\hline Less knowledge of academic writing & Yes & Yes \\
\hline $\begin{array}{l}\text { Lack of the knowledge about "Refer- } \\
\text { encing” others ideas and characteristics } \\
\text { of academic integrity }\end{array}$ & Yes & Yes \\
\hline $\begin{array}{l}\text { International students using English as } \\
\text { a second language face difficulties of } \\
\text { academic writing }\end{array}$ & Yes & No \\
\hline $\begin{array}{l}\text { Lack of confidence about subject mate- } \\
\text { rials and rationale }\end{array}$ & Yes & No \\
\hline Find subject content uninteresting & Yes & No \\
\hline $\begin{array}{l}\text { Doing part/full time jobs or other dis- } \\
\text { tractions, hence, less time allocation for } \\
\text { understand subject material in depth }\end{array}$ & Yes & No \\
\hline $\begin{array}{l}\text { Lack of critical thinking skills and the } \\
\text { skill of student's self-confidence }\end{array}$ & Yes & No \\
\hline $\begin{array}{l}\text { Distance learning students more prone } \\
\text { to obtain high plagiarism content }\end{array}$ & Yes & No \\
\hline $\begin{array}{l}\text { Encouragement for a surface approach } \\
\text { to answer repeated questions from pre- } \\
\text { vious years (Cox, 2008) }\end{array}$ & No & Yes \\
\hline $\begin{array}{l}\text { No access to the subject lecturer for the } \\
\text { extra time for the assistance for the } \\
\text { some tough materials of subject } \\
\text { (Feldman, 1989) }\end{array}$ & No & Yes \\
\hline $\begin{array}{l}\text { Inadequate and awareness of the subject } \\
\text { and objective of the assignments }\end{array}$ & Yes \\
\hline $\begin{array}{l}\text { Less transparency of course objectives } \\
\text { and requirements (Feldman, 1989) }\end{array}$ & No & Yes \\
\hline $\begin{array}{l}\text { Proving less constructive questions in } \\
\text { the assignments, hence, students are } \\
\text { prone to plagerise }\end{array}$ & No \\
\hline $\begin{array}{l}\text { The main focus of the international stu- } \\
\text { dents are earning money rather learning } \\
\text { the subject }\end{array}$ & Yes \\
\hline $\begin{array}{l}\text { Setting up a low exclude word count } \\
\text { consecutive words) }\end{array}$ & No \\
\hline
\end{tabular}

of surface learning, resulting in higher rates of plagiarism. Therefore, the nature of the questions also led to know whether students are learning in a deep or surface approach.

\begin{tabular}{|l|c|c|c|c|c|c|c|c|}
\hline Assignment No & \multicolumn{9}{|c|}{ Number of Draft Submissions } & \multicolumn{4}{c|}{ Number of Final Submissions } \\
\hline & $\begin{array}{c}\text { Sample } \\
\text { Size }\end{array}$ & Mean (SD) & $\begin{array}{c}\text { Geometric } \\
\text { Mean (GSD) }\end{array}$ & $\begin{array}{c}\text { Similarity\% } \\
<\mathbf{5 0 \%}\end{array}$ & $\begin{array}{c}\text { Sample } \\
\text { Size }\end{array}$ & Mean (SD) & $\begin{array}{c}\text { Geometric } \\
\text { Mean (GSD) }\end{array}$ & $\begin{array}{c}\text { Similarity \% } \\
<\mathbf{5 0 \%}\end{array}$ \\
\hline \multicolumn{7}{|c|}{ Subject A } \\
\hline Assignment 01 & 44 & $66.38(19.40)$ & $63.24(1.38)$ & 22.72 & 50 & $64.48(18.95)$ & $61.37(1.39)$ & 24 \\
\hline
\end{tabular}

This article is protected by copyright. All rights reserved. 


\begin{tabular}{|c|c|c|c|c|c|c|c|c|}
\hline Assignment 02 & 37 & $62.29(24.35)$ & 56.68 (1.59) & 29.72 & 48 & $65.02(23.40)$ & $59.90(1.54)$ & 25 \\
\hline \multicolumn{9}{|c|}{ Subject B } \\
\hline Assignment 01 & 17 & 72.41 (16.54) & 70.40 (1.27) & 11.78 & 18 & 69.77 (20.69) & 65.86 (1.45) & 16.66 \\
\hline Assignment 02 & 10 & $68.20(17.42)$ & $65.98(1.30)$ & 10 & 15 & $73.17(20.40)$ & $68.98(1.48)$ & 0 \\
\hline \multicolumn{9}{|c|}{ Subject C } \\
\hline Assignment 01 & 85 & 53.89 (29.29) & $0(0)$ & 45.88 & 79 & $47.97(27.78)$ & $0(0)$ & 58.22 \\
\hline Assignment 02 & 74 & $53(28.01)$ & $42.06(2.25)$ & 45.94 & 71 & $49.87(27.66)$ & $39.16(2.27)$ & 53.52 \\
\hline \multicolumn{9}{|c|}{ Subject D } \\
\hline Assignment 01 & 14 & $24.28(29.36)$ & $0(0)$ & 78.57 & 17 & $27.70(30.90)$ & $0(0)$ & 70.57 \\
\hline Assignment 02 & 18 & 22.61 (14.89) & $19.22(1.72)$ & 94.44 & 21 & 24.80 (14.86) & 20.94 (1.81) & 95.23 \\
\hline Assignment 03 & 15 & $43(32.21)$ & 33.09 (2.06) & 73.33 & 17 & 36.41 (29.94) & 24.06 (2.95) & 85.35 \\
\hline \multicolumn{9}{|c|}{ Subject E } \\
\hline Assignment 01 & 11 & 45.54 (23.79) & 40.05 (1.67) & 63.63 & 11 & 32.81 (14.70) & 29.77 (1.57) & 90.90 \\
\hline Assignment 02 & 11 & $36.54(20.24)$ & 31.89 (1.69) & 81.81 & 11 & 30.27 (12.95) & $27.83(1.51)$ & 90.90 \\
\hline \multicolumn{9}{|c|}{ Subject F } \\
\hline Assignment 01 & 141 & $60.06(21.52)$ & $54.43(1.66)$ & 29.78 & 141 & 58.63 (21.09) & 53.32 (1.63) & 32.62 \\
\hline Assignment 02 & 95 & 68.95 (21.36) & $0(0)$ & 18.94 & 120 & 73.29 (20.59) & 69.17 (1.46) & 14.16 \\
\hline \multicolumn{9}{|c|}{ Subject G } \\
\hline Assignment 01 & 12 & 33.91 (37.34) & $0(0)$ & 66.66 & 11 & 28.36 (34.01) & $0(0)$ & 72.72 \\
\hline Assignment 02 & 12 & $43(25.82)$ & $36.70(1.76)$ & 75 & 13 & $42.76(25.44)$ & $36.62(1.75)$ & 69.23 \\
\hline Assignment 03 & 10 & $51.30(33.50)$ & $0(0)$ & 50 & 8 & 38 (27.14) & $0(0)$ & 75 \\
\hline \multicolumn{9}{|c|}{ Subject $\mathrm{H}$} \\
\hline Assignment 01 & 7 & $8.28(7.84)$ & $5.92(2.27)$ & 100 & 10 & $16.10(10.96)$ & $11.68(2.49)$ & 100 \\
\hline Assignment 02 & 10 & $30.50(30.55)$ & $17.92(3.11)$ & 80 & 10 & $26.5(24.90)$ & $16.45(2.93)$ & 80 \\
\hline \multicolumn{9}{|c|}{ Subject I } \\
\hline Assignment 01 & 50 & $33.02(29.24)$ & $0(0)$ & 78 & 50 & 28.34 (28.37) & $0(0)$ & 82 \\
\hline Assignment 02 & 48 & 30.70 (26.47) & $20.93(2.49)$ & 81.25 & 48 & $27.31(24.38)$ & $19.28(2.32)$ & 85.91 \\
\hline \multicolumn{9}{|c|}{ Subject J } \\
\hline Assignment 01 & 32 & $42.43(28.14)$ & $30.57(2.64)$ & 65.62 & 31 & $39.03(24.83)$ & $28.20(2.68)$ & 67.74 \\
\hline Assignment 02 & 24 & 46.12 (31.65) & 28.13 (3.55) & 50 & 27 & $47.14(31.30)$ & 31.60 (3.17) & 51.85 \\
\hline \multicolumn{9}{|c|}{ Subject K } \\
\hline Assignment 01 & 124 & $46.08(24.74)$ & 37.79 (2.03) & 58.87 & 122 & $39.55(22.11)$ & $31.70(2.15)$ & 68.03 \\
\hline Assignment 02 & 109 & $46.56(25.92)$ & $37.53(2.11)$ & 55.96 & 103 & $39.16(23.23)$ & $30.90(2.18)$ & 66.01 \\
\hline
\end{tabular}

TABLE VIII 


\section{University Library}

\section{- M M N E R VA A gateway to Melbourne's research publications}

Minerva Access is the Institutional Repository of The University of Melbourne

Author/s:

Halgamuge, MN

Title:

The use and analysis of anti-plagiarism software: Turnitin tool for formative assessment and feedback

Date:

2017-11-01

Citation:

Halgamuge, M. N. (2017). The use and analysis of anti-plagiarism software: Turnitin tool for formative assessment and feedback. COMPUTER APPLICATIONS IN ENGINEERING EDUCATION, 25 (6), pp.895-909. https://doi.org/10.1002/cae.21842.

Persistent Link:

http://hdl.handle.net/11343/293028 